\title{
Genetic parameters and relationships between heifers rebreeding and hip height in Nellore cattle
}

\author{
Arione Augusti Boligon ${ }^{1}$, Lucia Galvão de Albuquerque ${ }^{2}$ \\ 1 Programa de Pós-Doutorado em Genética e Melhoramento Animal, FCAVIUNESP - Jaboticabal/SP. Scholar from FAPESP. \\ 2 Departamento de Zootecnia, FCAV/UNESP - Jaboticabal/SP. Fellowship from CNPq.
}

ABSTRACT - The objective of this study was to estimate heritability and verify the genetic correlations between heifers subsequent rebreeding with weaning hip height (WHH) and yearling hip height (YHH), using Bayesian inference. The (co)variance components and genetic parameters were estimated using an animal nonlinear (threshold) model for subsequent rebreeding and an animal linear model for WHH and YHH. The animal model included the contemporary group as the systematic effect and direct additive genetic and residual effects as random effects. Genetic maternal and maternal permanent environment effects were also considered in the model for WHH. Covariables considered were: rest period (linear effect), for subsequent rebreeding; animal age at measurement and age of cow at calving (linear and quadratic effects), for WHH and YHH. Direct heritability estimates were $0.14 \pm 0.04,0.45 \pm 0.03$ and $0.51 \pm 0.02$ for subsequent rebreeding, WHH and YHH, respectively. For maternal effects, the heritability of $\mathrm{WHH}$ and the proportion attributed to the permanent environmental effect were $0.08 \pm 0.02$ and 0.04 , respectively. The posterior means of genetic correlations estimates between subsequent rebreeding with WHH and YHH were $-0.16 \pm 0.05$ and $-0.21 \pm 0.04$, respectively. Selection response for subsequent rebreeding of heifers would be low. Increase in the rate of subsequent rebreeding could be obtained with improvements in the management applied to heifers. The inclusion of hip height in selection indices, especially when measured at yearling, promotes small reduction in the rate of subsequent rebreeding of Nellore heifers.

Key Words: Bayesian inference, beef cattle, heritability, reproductive trait

\section{Introduction}

The reproductive performance of beef cattle has received great emphasis in recent years, mainly because the reproductive traits affect the profitability and productivity of herds (Formigoni et al., 2005; Phocas et al., 1998). In beef cattle females, many fertility and reproductive efficiency indicative traits are categorical and have low heritabilitiy, and are not widely used in Brazilian breeding programs.

Although few studies have investigated heifer subsequent rebreeding in Zebu breeds, this trait can be considered an important point to be explored in beef cattle rearing systems. For Nellore cattle, Mercadante et al. (2003) reported difference of $20 \%$ between heifer subsequent rebreeding including all the females in relation to using only the primiparous females. Thus, the increase in heifer subsequent rebreeding rate can have a relevant impact on improving the livestock economic efficiency, since beef cows only generate income through direct sale of calves or when sold for slaughter.

The rebreeding of heifers is a binary trait and is defined as 1 (success) for heifers that conceive in the following breeding season and 0 (failure) for heifers that do not conceive, which enables the inclusion of information from all females in the analysis. Silva et al. (2008) reported heritability of 0.16 for subsequent rebreeding in Nellore heifers. Similarly, Doyle et al. (2000) obtained a heritability of 0.19 for subsequent rebreeding of Angus heifers.

Selection for higher weight or weight gains may result, by correlated response, in increase in adult weight and size of the animals (Boligon et al., 2009; Pereira et al., 2010; Boligon et al., 2011), which can increase the maintenance requirements. Thus, in primiparous females, the substantial physiological demands as a result of lactation and growth can cause a reduction in conception rates. However, in the literature, no studies found associating subsequent rebreeding of heifers and size indicator traits, such as hip height.

This study was conducted with the objective to estimate heritability for subsequent rebreeding of heifers and weaning hip height and yearling hip height of males and females using Bayesian inference, and to determine possible associations of subsequent rebreeding of heifers with weaning hip height and yearling hip height in Nellore cattle, in order to provide support for a genetic evaluation program on this breed. 


\section{Material and Methods}

Records from Nellore animals born between 1990 and 2006, belonging to Agropecuária Jacarezinho Ltda, located at the northwestern region of São Paulo State, Brazil, were analyzed. In the reproductive management adopted on the property, two breeding seasons occur: an anticipated breeding season, in which all heifers at about 15 and 16 months of age are exposed to reproduction, irrespective of body weight and body condition score, in order to identify sexual precociousness animals; and the normal breeding season, in which all the cows and non-pregnant heifers are exposed to sires. Heifers that did not become pregnant in the anticipated breeding season have a second chance in the normal breeding season. The females that do not conceive in the normal breeding season are discarded.

Pregnancy of the heifers is evaluated by rectal palpation approximately 60 days after the end of the anticipated breeding season. The following criteria are used to exclude females from the herd: failure to become pregnant in anticipate and normal breeding season, consecutively; cows that do not conceive within one year; low progeny performance; and a small percentage for health reasons.

Subsequent rebreeding was defined as a threshold trait, attributing a value of 1 (success) or 0 (failure) to heifers that had calved or not, respectively, given that they had calved once before. To perform the analysis, 1 (one) was added to these scores, i.e., 1 became failure and 2, success. The limiting date for rebreeding was 42 months of age.

Weaning and yearling hip height (WHH and YHH, respectively), were obtained in males and females weighing, using a height measuring stick midway-between the hipbones, at a point between the last lumbar and the first sacral vertebrae, immediately before the sacral bone, and thereon to the floor, expressed in centimeters (cm). Hip-height measurements only began to be applied from the year 2003 on.

For subsequent rebreeding, the contemporary group was defined as for herd and cow year of birth, calf sex and year of first calving. For WHH, the contemporary group consisted of the herd, year and season of birth, management group at birth and at weaning and sex. For YHH, the management group at yearling in a contemporary group is also included. Hip height records that were outside the range given by the contemporary group mean plus or minus three standard deviations and contemporary groups with less than four observations, were removed. For subsequent rebreeding, the contemporary groups without variation, i.e., all animals with the same value for the trait, 1 or 2 , were discarded (Table 1 ).

The (co)variance components and genetic parameters were estimated using Bayesian inference, considering a nonlinear linear animal model (threshold) for subsequent rebreeding and a linear animal model WHH and YHH, using the THRGIBBSF90 program (Misztal, 2002), in three-trait analysis. The model used can be described as follows:

$\mathrm{y}=\mathrm{X} \beta+\mathrm{Z}_{1} \mathrm{a}+\mathrm{Z}_{2} \mathrm{~m}+\mathrm{Z}_{3} \mathrm{C}+\mathrm{e}$

where $y$ is the vector of observed traits (subsequent rebreeding, weaning and yearling hip height); $\beta$ is the vector of systematic effects; $a$ is the vector of direct additive genetic effects; $m$ is the vector of maternal genetic effects; $\mathrm{c}$ is the vector of maternal permanent environmental effects; $\mathrm{X}$ is the incidence matrix for systematic effects (associate the $\beta$ vector to the $y$ vector), $Z_{1}$ is the incidence matrix of random additive genetic effects (associate the a vector to the $y$ vector), $Z_{2}$ is the incidence matrix of random maternal genetic effects (associate the $\mathrm{m}$ vector to the y vector), $\mathrm{Z}_{3}$ is the incidence matrix of random maternal permanent environmental effects (associate the c vector to the $\mathrm{y}$ vector); and e is the vector of residual effects. It was assumed that the direct additive genetic, maternal genetic and maternal permanent environmental effects were not correlated with the residual effect. Maternal genetic and maternal permanent environmental effects were only included in the model for WHH.

In the model, the following assumptions are established:

$$
\operatorname{Var}\left[\begin{array}{c}
a \\
m \\
c \\
e
\end{array}\right]=\left[\begin{array}{cccc}
G \otimes A & \operatorname{Cov}(a, m) \otimes A & 0 & 0 \\
\operatorname{Cov}(m, a) \otimes A & M \otimes A & 0 & 0 \\
0 & 0 & C \otimes I_{N m} & 0 \\
0 & 0 & 0 & R \otimes I_{N}
\end{array}\right]
$$

Table 1 - Description of the data file analyzed

\begin{tabular}{lcc}
\hline & Subsequent rebreeding & Weaning hip height \\
\hline Observation number & 15,091 & 13,102 \\
Mean \pm standard deviation & $0.73 \pm 0.46^{1}$ & $116.04 \pm 4.41^{2}$ \\
Number of dams & 10,782 & 9,890 \\
Number of sires & 334 & 190 \\
Number of contemporary groups & 81 & 204 \\
\hline
\end{tabular}

\footnotetext{
${ }^{1}$ Measurement in percentage.
}

${ }^{2}$ Measurement in centimeters. 
where $G$ is the (co)variance matrix of the direct additive genetic effect; $\otimes$ denotes the direct product between matrices; $A$ is the matrix of the numerators of the Wright relationship coefficients between individuals; $M$ is the (co)variance matrix of the maternal genetic effect; $C$ is the (co)variance matrix of the maternal permanent environmental effect; $I$ is an identity matrix; $R$ is the (co)variance matrix of the residual effect; $\mathrm{Nm}$ is the number of dams of animals with records, and $N$ is the number of animals with records.

The vectors $\beta$, a, $m$ and $c$ are location parameters of the conditional distribution $\mathrm{y} \mid \beta$, a, m, c. A priori was assumed to be a uniform distribution of $\beta$, which reflects a vague prior knowledge about this vector. For the (co)variance components of random effects, inverted Wishart distributions were defined as a priori. Thus, for continuous traits (WHH and $\mathrm{YHH}$ ), the distribution of $\mathrm{y}$, given the parameters of location and scale, was assumed as:

$(\mathrm{y} \mid \beta, \mathrm{a}, \mathrm{m}, \mathrm{c}, \mathrm{R}) \sim \mathrm{N}\left[\mathrm{X} \beta+\mathrm{Z}_{1} \mathrm{a}+\mathrm{Z}_{2} \mathrm{~m}+\mathrm{Z}_{3} \mathrm{c}, \mathrm{I}_{\mathrm{N}} \mathrm{R}\right]$

The subsequent rebreeding is a threshold trait and, according to Falconer \& Mackay (1996), the understanding of the inheritance of such traits lies in the idea that the trait has an underlying continuity with a threshold which imposes a discontinuity on the visible expression of the trait. Therefore, it is assumed that the underlying distribution $\left(\mathrm{I}_{\mathrm{SR}}\right)$ is determined by:

$\mathrm{I}_{\mathrm{SR}} \sim \mathrm{N}\left(\mathrm{X} \beta+\mathrm{Z}_{1} \mathrm{a}, \mathrm{I}_{\mathrm{e}}{ }^{2}\right)$

The initial distributions for direct additive genetic and residual effects followed multivariate normal distributions: $\mathrm{P}\left(\mathrm{a} \mid \sigma_{\mathrm{a}}^{2}\right) \sim \mathrm{N}\left(0, A \otimes \Sigma_{a}\right)$ $\mathrm{P}\left(\mathrm{e} \mid \sigma_{\mathrm{e}}^{2}\right) \sim \mathrm{N}\left(0, I \otimes \Sigma_{e}\right)$

Since the variable in the underlying distribution is not observable, the assumption of $\sigma^{2}{ }_{e}=1$ is generally adopted in order to obtain identifiability in the likelihood function (Gianola \& Sorensen, 2002). According to Gianola \& Foulley (1983), after definition of the model parameters, the connection between categorical and continuous scales can be established in such a way that the probability of an observation belonging to the first category is proportional to: $\mathrm{P}\left(\mathrm{y}_{\mathrm{r}}=1 \mid \mathrm{t}, \theta\right)=\mathrm{P}\left(\mathrm{I}_{\mathrm{r}}<\mathrm{t} \mid \mathrm{t}, \theta\right)=\phi\left(\left(\mathrm{t}-\mathrm{W}_{\mathrm{r}}^{\prime} \theta\right) / \sigma_{\mathrm{e}}\right)$ where $y_{\mathrm{r}}$ is the response variable for the rth observation, assuming a value of 1 or 2 if the observation belongs to the first or second category, respectively; $t$ is the threshold; since this value cannot be estimated, an arbitrary value is attributed; $\mathrm{I}_{\mathrm{r}}$ is the value of the underlying variable for the observation mentioned; $\phi()$ is the cumulative distribution function of a normal standard variable; $W_{\mathrm{r}}$ ' is the incidence column vector that relates $\phi$ to the $\mathrm{r}^{\text {th }}$ observation; $\phi=\left(\mathrm{b}^{\prime}, \mathrm{a}^{\prime}\right)$ is the vector of location parameters of order $s$ with $b$ (systematic effects) and a (random effects).
In this study, the threshold-linear model can be represented as (Varona et al., 1999):

$$
\left(\begin{array}{c}
y_{w h h} \\
y_{y h h} \\
I_{s r}
\end{array}\right) \sim N\left(\begin{array}{cccc}
X \beta_{w h h} & +Z_{1} a_{w h h} & +Z_{2} m_{w h h} & +Z_{3} c_{w h h} \\
X \beta_{y h h} & +Z_{1} a_{y h h} & , I \otimes R \\
X \beta_{s r} & +Z_{1} a_{s r} &
\end{array}\right)
$$

where $\mathrm{R}$ is a $3 \times 3$ residual (co)variances matrix.

For subsequent rebreeding, the animal model included, as systematic effects, the contemporary group and linear effect of the rest period (number of days after calving until the beginning of the second breeding season), as a covariate; in addition to direct additive genetic and residual, as random effects. For WHH and YHH, the systematic effects were: contemporary group and animal age at measurement (linear and quadratic effects) and age of cow at calving (linear and quadratic effects) as covariates; in addition to direct additive genetic and residual, as random effects. Maternal additive genetic and permanent environmental effects also were considered as random effects for WHH.

A total of 1,100,000-gibb sampling were generated. Burn-in period of 200,000 iterations with samples taken each 20 cycles were considered to obtain the herdabilities and correlations posterior distributions. The burn-in period and the sampling interval were established empirically. The convergence was verified through graphical inspection (trace-plots) of the sampled values versus iterations and using the criteria proposed by Geweke (1992). In the Geweke test, initial values of the Markov chain are compared with final values of the chain in order to detect convergence failures. Rejection of the null hypothesis indicates convergence. Thus, probabilities lower than 0.05 indicate the existence of evidence against the convergence of chains.

\section{Results and Discussion}

For all parameters estimated, the results indicated that the burn-in period considered was sufficient to reach convergence (Table 2). The heritability estimated showed little difference in mean, median and mode values, indicating a possible symmetry in the posterior distributions of the parameters. Moreover, convergence was achieved with low standard deviation and a relatively short $95 \%$ highest posterior density interval.

The heritability estimated, given by the posterior mean, obtained for heifers subsequent rebreeding was low, indicating that this trait is strongly influenced by environmental factors. However, although improvements in animal management are faster alternatives to reduce the expression of this trait, long-term selective processes should 
Table 2 - Descriptive statistics of posterior distributions from direct heritability for subsequent rebreeding, weaning and yearling hip height in Nellore cattle

\begin{tabular}{lccc}
\hline Parameters & Subsequent rebreeding & Weaning hip height & Yearling hip height \\
\hline Mean \pm standard deviation & $0.14 \pm 0.04$ & $0.45 \pm 0.03$ & 0.44 \\
Mode & 0.14 & 0.45 & $0.51 \pm 0.02$ \\
Median & 0.15 & 0.39 to 0.50 & 0.52 \\
Highest posterior density interval (95\%) & 0.09 to 0.19 & 0.604 & 0.44 to 0.56 \\
Probability & 0.492 & 0.671 \\
\hline
\end{tabular}

${ }^{1}$ Geweke convergence test. If significant, $(\mathrm{P}<0.05)$ indicates non-convergence.

have a positive impact on cattle productivity, because even small increases in conception rates of heifers should contribute to improvements in reproductive efficiency in beef cattle.

For subsequent rebreeding trait of heifers, the posterior mean value of heritability obtained in this study $(0.14 \pm 0.04)$ was similar to the value of 0.16 reported by Silva et al. (2008) for Nellore females sexually precocious using Bayesian inference. Mercadante et al. (2003) estimated heritability of $0.10 \pm 0.07$ for subsequent rebreeding of Nellore heifers at 3 years of age using a threshold animal model.

Using part of the same dataset analyzed in the present study, Pereira (2008) related mean heritability values of $0.15 \pm 0.04$ and $0.05 \pm 0.02$ for subsequent rebreeding rate of females exposed at 24 months of age (normal breeding season) and when including all females (exposed at 16 and 24 months of age), respectively. According to the same author, the inclusion of data from sexually precocious animals reduced genetic variability and consequently, the estimated heritability.

Using a nonlinear model implemented by the R method, Doyle et al. (2000) reported heritability of 0.19 for rebreeding rate in Angus heifers. However, these authors suggested caution using these results, since half the subsample estimates were outside the parameter space (with credibility interval of $95 \%$ ranging from 0.000 to 0.395 ). On the other hand, using the same methodology (Method R), Pereira (2008) estimated heritability of $0.05,0.07$ and 0.01 for subsequent rebreeding in Nellore heifers exposed at 24 months of age (normal breeding season), 16 months of age (anticipated breeding season) and considering all the females, respectively.

The direct heritability values estimated for weaning hip height and yearling hip height were moderate (Table 2), indicating that a substantial part of the variation in these traits is determined by the additive action of genes and that these traits should respond to selection. Thus, the selection of animals with null genetic values (close to zero) for hip height at weaning and/or at yearling should be used in production systems in which medium size animals are desirable.
The posterior mean of direct heritability for hip height obtained in this study is close to those reported in the literature for Nelore cattle (Yokoo et al., 2007; Pereira et al., 2010). On the other hand, for the Brahman breed animals, Vargas et al. (2000) reported higher values of direct heritability for weaning hip height and yearling hip height, with values of 0.73 and 0.87 , respectively.

With respect to maternal effects for hip height at weaning, the posterior mean of heritability estimates and the posterior mean attributed to the permanent environmental effect showed low magnitude, with values of $0.08 \pm 0.02$ and 0.04, respectively. For Brahman cattle, Vargas et al. (2000) reported maternal heritability of 0.10 for weaning hip height.

The posterior means of genetic correlations between heifers subsequent rebreeding and weaning hip height and yearling hip height were negative (Table 3 ). These results indicate that animals with higher hip height, especially when measured at yearling, have less capacity to conceive in the following breeding season. Thus, the inclusion of hip height in beef cattle selection indexes may promote, in a long term, lower subsequent rebreeding rates of primiparous Nellore females.

It should be noted that studies describing estimates of genetic correlations between subsequent rebreeding and hip height of heifers were not found in the literature. However, recent studies have shown negative genetic correlation and with high magnitude between subsequent rebreeding of heifers and yearling weight, i.e., $-0.66 \pm 0.05$ (Pereira, 2008). According to Pereira et al. (2010) and Boligon et al. (2011), selection for higher weights or weight gains can lead to selection of animals with greater stature and size, which can be more demanding in terms of nutrition.

The subsequent rebreeding is a trait measured relatively late, expressed in only one sex, and showing low heritability (Table 2). Thus, selection only for this trait may not be a good alternative for improvements in reproductive performance of beef cattle. In this context, improvements in the fertility of beef cattle raised in Brazil could be obtained considering the subsequent rebreeding rate of females in 
Table 3 - Posterior density of genetic and residual correlations between subsequent rebreeding and continuous traits (weaning hip height and yearling hip height) of Nellore heifers

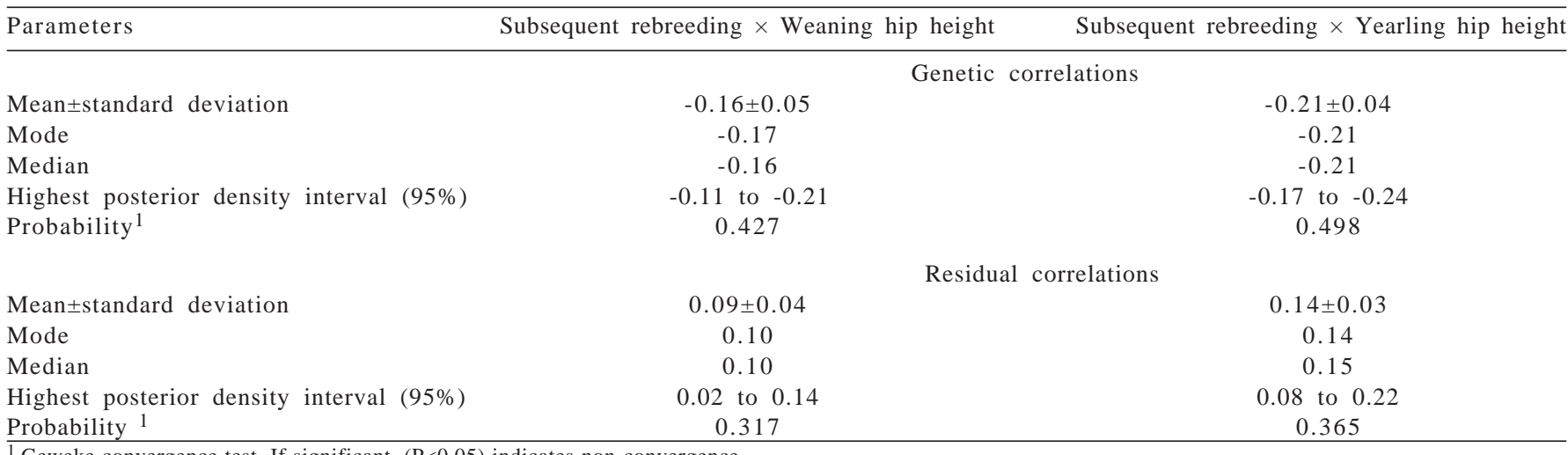

${ }^{1}$ Geweke convergence test. If significant, $(\mathrm{P}<0.05)$ indicates non-convergence.

the selection indices, along with other traits that are already being used as selection criteria, as weights obtained at young ages, carcass traits and scrotal circumference.

\section{Conclusions}

Small genetic gains with the inclusion of rebreeding of steers in selection programs are expected. Increase in the rate of subsequent rebreeding could be obtained with improvements in the management applied to heifers. The inclusion of hip height in the selection indices, especially when measured at yearling, results in small reduction in the rate of subsequent rebreeding of Nellore heifers.

\section{References}

BOLIGON, A.A.; ALBUQUERQUE, L.G.; MERCADANTE, M.E.Z. et al. Herdabilidades e correlações entre pesos do nascimento à idade adulta em rebanhos da raça Nelore. Revista Brasileira de Zootecnia, v.38, p.2320-2326, 2009.

BOLIGON, A.A.; BALDI, F.; ALBUQUERQUE, L.G. Genetic parameters and relationships between growth traits and scrotal circumference measured at different ages in Nellore cattle. Genetics and Molecular Biology, v.34, p.225-230, 2011.

DOYLE, S.P.; GOLDEN, B.L.; GREEN, R.D. et al. Additive genetic parameter estimates for heifer pregnancy and subsequent reproduction in Angus females. Journal of Animal Science, v.78, p.2091-2098, 2000.

FALCONER, D.S.; MACKAY, F.C. Introduction to quantitative genetics. 4.ed. Harlow, England: Longmans Green, 1996. 464p.

FORMIGONI, I.B.; FERRAZ, J.B.S.; SILVA, J.A.II.V. et al. Valores econômicos para habilidade de permanência e probabilidade de prenhez aos 14 meses em bovinos de corte. Arquivo Brasileiro de Medicina Veterinária e Zootecnia, v.57, p.220-226, 2005.

GEWEKE, J. Evaluating the accuracy of sampling-based approaches to the calculation of posterior moments. In: BERNARDO, J.M.;
BERGER, J.O.; DAWID, A.P. et al. (Eds.) Bayesian statistics. New York: Oxford University Press, 1992. p.625-631.

GIANOLA, D.; FOULLEY, J.L. Sire evaluation for ordered categorical data with a threshold model. Genetics Selection Evolution, v.15, p.201-224, 1983.

GIANOLA, D.; SORENSEN, D. Likelihood, Bayesian, and MCMC methods in quantitative genetics. New York: Springer, 2002. 720p. (Statistics for Biology and Health).

MERCADANTE, M.E.Z.; PACKER, I.U.; RAZOOK, A.G. et al. Direct and correlated responses to selection for yearling weight on reproductive performance of Nelore cows. Journal of Animal Science, v.81, p.376-384, 2003.

MISZTAL, I. 2010. THRGIBBSF90 family of programs. Available at: $<$ http://nce.ads.uga.edu/ ignancy/newprograms.html $>$. Accessed on: Feb. 2, 2010.

PEREIRA, M.C.; YOKOO, M.J.I.; BIGNARDI, A.B. et al. Altura da garupa e sua associação com características reprodutivas e de crescimento na raça Nelore. Pesquisa Agropecuária Brasileira, v.45, n.6, p.613-620, 2010.

PEREIRA, M.C. Avaliação genética da reconcepção de fêmeas primíparas da raça Nelore. 2008. 73f. Tese de Doutorado (Doutorado em Zootecnia) - Universidade Estadual Paulista, Faculdade de Ciencias Agrarias e Veterinarias, Jaboticabal.

PHOCAS, F.; BLOCH, C.; CHAPELLE, P. Developing a breeding objective for a French purebred beef cattle selection programme. Livestock Production Science, v.57, p.49-65, 1998.

SILVA, J.A.II.V.; BIGNARDI, A.B.; ELER, J.P. et al. Análises alternativas no estudo da reconcepção de novilhas Nelore. Boletim de Indústria Animal, v.65, p.131-135, 2008.

VARGAS, C.A.; ELZO, M.A.; CHASE JR., C.C. et al. Genetic parameters and relationships between hip height and weight in Brahman cattle. Journal of Animal Science, v.78, p.3045-3052, 2000.

VARONA, L.; MISZTAL, I.; BERTRAND, J.K. Threshold-linear versus linear-linear analysis of birth weight and calving ease using an animal model: I. Variance component estimation. Journal of Animal Science, v.77, p.1994-2002, 1999.

YOKOO, M.J.I.; ALBUQUERQUE, L.G.; LOBO, R.B. et al. Estimativas de parâmetros genéticos para altura do posterior, peso e circunferência escrotal em bovinos da raça Nelore. Revista Brasileira de Zootecnia, v.36, n.6, p.1761-1768, 2007. 